\title{
Sustainability perspectives in agricultural economics research and policy agenda
}

\author{
Bernardo Corrado de Gennaro ${ }^{1}$ and Maria Bonaventura Forleo ${ }^{2^{*}}$ (D)
}

\author{
* Correspondence: forleo@unimol.it \\ 2Department of Economics, \\ University of Molise, Via de Sanctis, \\ 86100 Campobasso, Italy \\ Full list of author information is \\ available at the end of the article
}

\begin{abstract}
Background: The agricultural sector both needs to reduce its impacts and adapt its food production system to cope with environmental constraints and climate changes. This special issue includes three selected papers presented at the 53rd annual Conference of the Italian Society of Agricultural Economics discussing the future of agriculture. The fil rouge linking the three papers is the issue of sustainability that nowadays influences the functioning of the food supply chain and the behavior of all actors involved in it, from producers to consumers.

Findings: The selected papers investigate the theme of sustainability by exploring strategies for the adoption of sustainable innovation in the food supply chain, developing a model that assesses the effect of climate changes on farm production, as well as evaluating consumer attitudes to wine attributes, including those related to "carbon footprint" and "winescape esthetic."

Conclusions: The reading of these papers provides a multifaceted light on different dimensions linking future perspectives of sustainable agriculture between globalization and local market. Papers discuss issues, propose approaches, and show empirical findings that can be useful to fuel the debate about future agricultural policies and stimulate the development of research agendas.
\end{abstract}

Keywords: Climate change, Sustainable innovations, Wine purchasing behavior, Millennials

\section{Introduction}

Agriculture both contributes to sustainability along its main three pillars, balancing economic, environmental, and social performances, and is affected by their dynamics. A vision for sustainable agriculture based on five criteria and on several actions has been proposed for transforming world food and agriculture sectors in order to achieve the United Nations Sustainable Development Goals and embrace the 2030 Agenda's vision of sustainable development (FAO, 2016, 2018).

Regarding the environmental sphere, climate change issues in agriculture are of importance and, since the creation of the Intergovernmental Panel on Climate Change (IPCC) within UNEP in 1998, have gained new momentum in recent international events and initiatives. The agricultural sector both needs to reduce its impacts and adapt its food production system to cope with environmental constraints and climate changes. Furthermore, from the Paris Agreement of 2015, the COP24 Conference of the Parties held in December 2018 marked the start of the Koronivia Joint Work on

(c) The Author(s). 2019 Open Access This article is distributed under the terms of the Creative Commons Attribution 4.0 International License (http://creativecommons.org/licenses/by/4.0/), which permits unrestricted use, distribution, and reproduction in any medium, provided you give appropriate credit to the original author(s) and the source, provide a link to the Creative Commons license, and indicate if changes were made. 
Agriculture. Climate change-induced increases in temperatures, rainfall variation, and the frequency and intensity of extreme weather events are adding to pressures on global and local agricultural and food systems. Climate change is expected to affect negatively both crop and livestock production systems in most regions, although with different patterns (OECD / IFPRI 2014). Faced with growing global demand, market and warming phenomena, and with competition for resources, agricultural policiesthe next CAP is one of the most obvious policy spheres-are called to help to mitigate the effect of climate and to adapt to climate changes with measures at the farm and sectorial levels aimed at reducing their vulnerabilities (EEA 2015). Within the above context, a growing body of literature has started to address the topic of relationships between agriculture, sustainability, and climate changes, both coping with risks related to different climate scenarios and regions, and with measures fostering the adoption of innovations induced by and oriented towards sustainability.

Another field of research is the investigation of new modes of supply chain sustainability governance and new models of multi-stakeholder collaboration to achieve food security, environmental sustainability, and economic development (WEF 2016). Among the three factors that Gardner et al. (2018) consider as having a pivotal role in determining whether commodity production and trade can be placed on a more sustainable pathway, the issue of scale and that of responsibility are particularly relevant in the present context. The issue of scale refers to the global versus local debate and underlines the disconnection between the territories involved as drivers and impacts, between places of production and of consumption. The second issue points to the topic of responsibility and to the need for actors involved in every step of global-local supply chains to share the responsibility of placing production systems on a more sustainable footing. The increasing array of multi-stakeholder processes, roundtables, and hybrid governance arrangements and the wider set of state and non-state actors urge the need for transparency and information, and new governance models along the food chains.

Environmental and economic perspectives are even more closely linked with sociocultural and ethical issues, such as the issue of hunger, and with the challenge of providing a growing global population with healthy diets from sustainable food systems (Willett et al. 2019). In this regard, the literature has increasingly paid attention to the pro-environmental attitude and behavior towards more sustainable food consumption and diet styles (FAO 2010). Sustainable claims, environmental values, consumer sensitivity, and marketing strategies are among the most used key words in the field. The wine industry is one of the most studied sectors within the literature addressing the issues of sustainability in the agriculture sphere, considering both the supply side and the demand side. In the search for new business models and marketing tools to address the increasing competition on the world and local levels, there have been many studies, projects, and initiatives promoting sustainability-oriented practices and approaches in the wine sector. On the institutional level, in 2011 the Italian Ministry for the Environment, Land and Sea launched the project VIVA - Sustainable wine, Sustainability and Culture to improve the sustainability performances of the wine chain by means of a new methodological approach and a program in which several Italian wine-growing firms participated. The Millennial generation, maybe because of the intrinsic nature of inter-generationality within the sustainability concept, or because of their degree of sensitivity towards sustainable issues, are increasingly studied for their 
relevance in forecasting future scenarios and in comparing food and beverage habits among generations.

This special issue includes three selected papers presented at the 53rd annual Conference of the Italian Society of Agricultural Economics (SIDEA), held in San Michele all'Adige/Bolzano on 22-24 September 2016. The theme of the Conference was, "The future of agriculture between globalization and local markets." The choice of this theme aimed to stimulate a scientific debate on the future of an agriculture that is marked by the dualism of opening global markets and the growing demand for local products linked to the territory and traditions. Indeed, the Conference intended to discuss how the dichotomy of liberalism versus localism involves multiple challenges for the agriculture and the food sector.

\section{Report}

The papers included in this special issue focus on the theme of sustainability. All of them point out how this topic affects all the actors involved in the food supply chain and cover three main research areas. These are the adoption of sustainable innovation in the food supply chain, the development of a model that is able to predict the effect of climate changes on farm productivity, and the assessment of consumer preferences for sustainable food products.

The paper by Pancino et al. (2019) sheds light on the process of designing a multistakeholder partnership for the adoption of sustainable innovations in the food supply chain. Authors qualitatively analyze the Barilla Sustainable Farming initiative to draw indications about the most suitable strategies for implementing sustainable innovations. The multi-stakeholder partnership increases the chances of implementing sustainable innovations in the food supply chain: both farmers and other food supply chain stakeholders need to be committed to developing sustainable innovation. Sharing information, communication about common sustainable goals, and shared assessments of sustainable practices are important requirements for developing and adopting effective sustainable innovations.

The paper by Onofri et al. (2019) develops and tests a methodology to assess and predict the effects of climate change on agricultural production. The authors develop a twostage method that econometrically estimates the marginal product of key production inputs (e.g., labor and land) and then predicts future agricultural sector performances using different IPCC scenarios. Such methodology is applied in order to predict the agricultural performances of the Veneto region in 2030. Results differ according to the selected IPCC scenario selected and consequent input use variations. However, the authors point out that climate change adaptation and mitigation policies are a priority and need to be implemented to preserve the land productivity in the area analyzed.

The paper by Gallenti et al. (2019) explores Italian Millennials' attitudes to wine attributes, including those related to "carbon footprint" and "winescape esthetic." The authors perform a choice experiment to define the ordinal ranking of preferences for the many wine attributes, as well as to assess the individual willingness to pay (WTP) for the key product characteristics, including those related to the sustainability of the production method. The authors, sampling 587 respondents, detected considerable heterogeneity in preferences and WTP. The majority of respondents interested in the "carbon footprint claim" is also willing to pay a premium price to consume high-quality wines. 
Instead, the authors found that "winescape esthetic" does not appear to be an important attribute in orienting respondents' preferences and no premium price is associated with this attribute.

\section{Conclusions}

The collection of articles included in this special issue sheds a multifaceted light on different dimensions linking future perspectives of sustainable agriculture between globalization and local market. These dimensions relate to future agricultural performances under different climate change scenarios, to the importance of designing multistakeholder partnership and contracts to implement sustainable innovations in value chains, and to the sensitivity of Millennials towards carbon footprint claims of wine. These papers discuss such issues, propose approaches, and show empirical findings that fuel future debate and stimulate the development of research agendas.

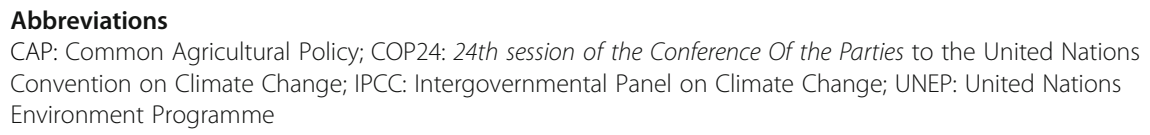

\section{Acknowledgements}

The authors would like to thank the Agricultural and Food Economics journal for having given visibility to the papers presented at the 53rd SIDEA Conference. This allows for the international diffusion of the debate developed between Italian agricultural economists.

\section{Authors' contributions}

MBF developed the Introduction section. Both authors developed the remaining sections and read and approved the final manuscript.

\section{Authors' information}

B.C. de Gennaro is an Associate Professor of the Agricultural Economics and Policy at the University of Bari, Italy. Email: bernardocorrado.degennaro@uniba.it

M.B. Forleo is an Associate Professor of the Agricultural Economics and Rural Appraisal at the University of Molise, Campobasso, Italy. E-mail: forleo@unimol.it

\section{Competing interests}

Both authors declare that they have no competing interests.

\section{Author details}

${ }^{1}$ Department of Agricultural and Environmental Sciences (DiSAAT), University of Bari, Via G. Amendola, 165 Bari, Italy.

${ }^{2}$ Department of Economics, University of Molise, Via de Sanctis, 86100 Campobasso, Italy.

Received: 11 June 2019 Accepted: 26 June 2019

Published online: 30 July 2019

\section{References}

EEA (2015) Agriculture and climate change Available at: https://www.eea.europa.eu/signals/signals-2015/articles/agricultureand-climate-change. European Environment Agency, Copenhagen

FAO (2010) Definition of sustainable diets. International scientific symposium: biodiversity and sustainable diets united against hunger, Rome, Italy, 3-5 November 2010. Available at: http://www.fao.org/ag/humannutrition/285070e8d8dc364ee46865d5841c48976e9980.pdf

FAO (2016) Sustainable value chains for sustainable food systems. FAO, Rome. Available at: http://www.fao.org/3/a-i6511e.pdf

FAO (2018) Transforming food and agriculture to achieve the SDGs 20 interconnected actions to guide decision-makers. FAO, Rome. Available at: http://www.fao.org/3/19900EN/i9900en.pdf

Gallenti G, Troiano S, Marangon F, Bogoni P, Campisi B, Cosmina M (2019) Environmentally sustainable versus aesthetic values motivating millennials' preferences for wine purchasing: evidence from an experimental analysis in Italy. Agric Food Econ https://doi.org/10.1186/s40100-019-0132-x

Gardner TA, Benzie M, Börner J., et al. (2018) Transparency and sustainability in global commodity supply chains. World Dev doi: https://doi.org/10.1016/j.worlddev.2018.05.025. in press

OECD / IFPRI (2014) Modelling adaptation to climate change in agriculture. OECD Food, Agriculture and Fisheries Papers, No. 70. https://doi.org/10.1787/5jxrclljnbxq-en

Onofri L, Bianchin F, Boatto V (2019) How to assess future agricultural performance under climate change? A case-study on the Veneto region. Agric Food Econ https://doi.org/10.1186/s40100-019-0131-y

Pancino B, Blasi E, Rappoldt A, Pascucci S, Ruini L, Ronchi C (2019) Partnering for sustainability in agri-food supply chains: the case of Barilla Sustainable Farming in the Po Valley. Agric Food Econ https://doi.org/10.1186/s40100-019-0133-9 
WEF World Economic Forum (2016) Building partnerships for sustainable agriculture and food security: a guide to countryled action. World Economic Forum, Geneva. Available at: https://www.weforum.org/whitepapers/building-partnershipsfor-sustainable-agriculture-and-food-security-a-guide-to-country-led-action

Willett W, Rockström J, Loken B et al (2019) Food in the Anthropocene: the EAT-Lancet Commission on healthy diets from sustainable food systems. Lancet 393:447-492. https://doi.org/10.1016/S0140-6736(18)31788-4

\section{Publisher's Note}

Springer Nature remains neutral with regard to jurisdictional claims in published maps and institutional affiliations.

Submit your manuscript to a SpringerOpen ${ }^{\odot}$ journal and benefit from:

- Convenient online submission

- Rigorous peer review

- Open access: articles freely available online

- High visibility within the field

- Retaining the copyright to your article

Submit your next manuscript at $\boldsymbol{\nabla}$ springeropen.com 